\title{
AVALIAÇÃO CLÍNICA DE NÔVO AGENTE INIBIDOR DA MONAMINOXIDASE EM PACIENTES HOSPITALIZADOS
}

\author{
WALTER STOIANI \\ J. LAMARTINE DE ASSIS
}

Embora o uso do eletrochoque em geral proporcione bons resultados na terapêutica dos casos graves de depressão, nos últimos anos tem sido muito visada a possibilidade de substituí-lo por agentes psicotrópicos (psicanalépticos) ${ }^{3}$, pricipalmente nos casos em que o risco de suicídio não é iminente. O valor destas drogas é ressaltado se forem consideradas as contraindicaçōes da convulsoterapia. Sem dúvida, o aparecimento de novas drogas como os inibidores da monaminoxidase ${ }^{1}$, pràticamente desprovidas de toxidade nas doses habituais e dotadas de evidente efeito antidepressivo, abre novas perspectivas para o tratamento de desordens psíquicas que, até há bem pouco tempo, sòmente poderiam ser influenciadas pelos tratamentos clássicos.

\section{MATERIAL, METODO E RESULTADOS}

Foi utilizada em nossas observações clinicas a $\alpha$-metil-benzilidrazina *, nôvo agente hidrazinico inibidor da monaminoxidase.

Foram estudados 20 pacientes internados, todos do sexo masculino, com idade entre 18 a 75 anos. Os pacientes foram submetidos prèviamente a exame psíquico, exame clínico e, alguns, a exames laboratoriais (urina e hemograma). Todos apresentavam, como sintoma primário ou secundário, a depressāo do humor. As síndromes depressivas foram classificadas levando em conta a sintomatologia e os latôres etiopatogênicos. Não foi observado, nesta avaliação clínica, paralelamente, um grupo contrôle. O medicamento foi administrado por via oral em comprimidos de $5 \mathrm{mg}$, variando a dose diária de 10 a $20 \mathrm{mg}$. Foi usado, segundo Pichot ${ }^{2}$, o método de observação clínico-analítica mediante o qual um de nós, em entrevistas padronizadas, verificava a evolução da tendência depressiva. As entrevistas se repetiram com intervalos semanais e o contrôle clínico foi diário. $O$ tempo mais curto de tratamento foi de 20 dias e, o mais prolongado, de 90 dias.

Para melhor sistematização dos resultados foi adotado o seguinte critério de classificaçāo: a) remissão completa, com desaparecimento da inibição psicomotora, do risco de suicidio, da ansiedade e da autodepreciação, permitindo a volta à atividade normal; b) melhora acentuada, com possibilidade de volta à atividade rormal, mas sem que todos os elementos depressivos houvessem desaparecido, restando certo grau de ansiedade; c) melhora discreta, sendo os pacientes pouco influenciados, persistindo, embora ligeiramente melhoradas, as manifestações depressivas, inclusive as idéias de suicídio, nāo sendo possivel a volta às atividades normais; d) não influenciados.

Trabąlho realizado no Sanatório Anhembi (São Paulo).

* Actomol - fornecido pelo Laboratório Ayerst Ltda. 
Devido ao número reduzido de pacientes e às dificuldades de metodologia não foi feita análise estatística. Os doentes que mais se beneficiaram com o tratamento foram aquêles nos quais a depressão era reativa. Em seguida, os pacientes com neurose, os de idade mais avançada sem sinais de comprometimento orgânico (psicose involutiva) e um com psicose maniaco-depressiva. Nos demais casos, os resultados foram menos expressivos. Em alguns doentes com sintomas secundários (ansiedade, inquietação ou agitação psicomotora discreta) foram associados neurolépticos (butirofenona) ou tranquilizantes (clordiazepóxido) em doses adequadas, com bons resultados. Um paciente apresentou, no decorrer do tratamento, ictericia que regrediu prontamente com a suspensão da administração do medicamento. Os poucos efeitos colaterais observados (tonturas e bôca sêca) e apenas em um caso a ação hepatotóxica (icterícia) e que cederam prontamente com a diminuição ou suspensāo do medicamento, demonstram sua relativa inocuidade. Os resultados obtidos, relativamente a cada paciente, estão representados na tabela 1 . Os resultados globais de acôrdo com as formas de depressões, podem ser vistos na tabela 2 .

\begin{tabular}{|c|c|c|c|c|c|}
\hline $\begin{array}{l}\text { Pron- } \\
\text { tuário }\end{array}$ & $\begin{array}{l}\text { Idade } \\
\text { (anos) }\end{array}$ & Diagnóstico & $\begin{array}{c}\text { Dose } \\
(m g / \text { dia })\end{array}$ & $\begin{array}{c}\text { Resul- } \\
\text { tados }\end{array}$ & $\begin{array}{l}\text { Tempo de } \\
\text { tratamen- } \\
\text { to (dias) }\end{array}$ \\
\hline 7717 & 75 & Arteriosclerose cerebral & 15 & ++ & 40 \\
\hline 7751 & 34 & Neurose & 20 & ++ & 20 \\
\hline 7587 & 58 & Psicose involutiva & 15 & + & 60 \\
\hline 7670 & 39 & Neurose & 10 & 0 & 60 \\
\hline 7594 & 39 & Psicose pós-traumática & 15 & +++ & 90 \\
\hline 7742 & 57 & Psicose involutiva & 15 & ++ & 60 \\
\hline 7999 & 46 & Oligofrenia & 15 & ++ & 60 \\
\hline 8068 & 56 & Neurose & 10 & + & 60 \\
\hline 8045 & 56 & Psicose maniaco-depressiva & 15 & $+t+$ & 30 \\
\hline 7468 & 43 & Esquizofrenia & $15 / 20$ & 0 & 60 \\
\hline 7942 & 63 & Psicose maniaco-depressiva & 15 & + & 60 \\
\hline 7879 & 57 & Arteriosclerose cerebral & 10 & 0 & 30 \\
\hline 8157 & 52 & Esquizofrenia & 10 & 0 & 30 \\
\hline 7594 & 39 & Psicose reativa & 15 & +++ & 30 \\
\hline 7723 & 57 & Psicose reativa & 15 & $+t+$ & 30 \\
\hline 8188 & 56 & Neurose & 15 & ++ & 30 \\
\hline 7989 & 32 & Oligofrenia & 15 & ++ & 30 \\
\hline 8443 & 56 & Arteriosclerose cerebral & 20 & + & 30 \\
\hline 8320 & 63 & Psicose involutiva & 15 & ++ & 60 \\
\hline 8571 & 18 & Psicose reativa & 15 & +++ & 20 \\
\hline
\end{tabular}

Tabela 1 - Idade, diagnóstico, dosagens, tempo de tratamento e resultados em 20 pacientes com quadros depressivos.

\section{COMENTĀRIOS}

Nos três pacientes cuja depressão era reativa ocorreu remissão completa. Em três doentes com depressão involutiva pudemos observar resultados satisfatórios, embora menos expressivos do que nas depressões reativas, pois em dois houve melhora acentuada e em um apenas melhora discreta. Nas depressões neuróticas os resultados foram, também, menos efetivos que nas psicoses reativas pois, se em dois casos houve melhora acentuada, em outro a melhora foi discreta e um paciente não foi influenciado. 


\begin{tabular}{|c|c|c|c|c|c|}
\hline \multirow[t]{2}{*}{ Formas de depressões } & \multicolumn{4}{|c|}{ Resultados } & \multirow[t]{2}{*}{ Total } \\
\hline & +++ & ++ & + & 0 & \\
\hline Endógenas (PMD) & 1 & 一 & 1 & 一 & 2 \\
\hline Involutivas & - & 2 & 1 & - & 3 \\
\hline Reativas & 3 & - & - & - & 3 \\
\hline Neuróticas & - & 2 & 1 & 1 & 4 \\
\hline Sintomáticas * & 1 & 3 & 1 & 3 & 8 \\
\hline Totais & 5 & 7 & 4 & 4 & 20 \\
\hline
\end{tabular}

Tabela 2 - Ésquema dos resultados: +++ , remissão completa; ++ , melhora acentuada; +, melhora discreta; 0 , não influenciados. * Depressões no curso de psicoses aıversas: esquizofrenia, oligofrenia, arteriosclerose cerebral e psicose pós-traumática.

As depressōes no curso de psicoses diversas foram as que responderam de modo menos regular à droga, pois apenas em um caso houve remissão completa das manifestaçōes depressivas; tratava-se de depressão em psicose pós-traumática. Nos demais casos as respostas foram varáveis. Assim, dois oligofrênicos tiveram melhora acentuada do quadro depressivo, o mesmo não acontecendo em pacientes com arteriosclerose cerebral em que apenas um dentre três apresentou melhora acentuada dos sintomas depressivos. A depressão observada em dois esquizofrênicos não foi influenciada pelo medicamento. De dois pacientes com depressão endógena, um teve remissão completa e outro melhorou de modo discreto. $O$ número dêstes casos é pequeno para conclusão definitiva.

A análise da tabela 2 mostra os resultados globais nas diferentes formas de depressão, observando-se remissão completa em 5 doentes: três com depressão reativa, um dentre $8 \mathrm{com}$ psicose sintomática e um dos dois com psicose maníaco-depressiva. Em 7 casos houve melhoras acentuadas e em 8 melhoras discretas ou nenhuma melhora. Verifica-se, assim, que 16 doentes tiveram seus sintomas depressivos influenciados pela droga e sòmente 4 não apresentaram qualquer modificação. Dos 16 influenciados, 5 tiveram remissão total, 7 obtiveram melhoras acentuadas e apenas 4 foram pouco melhorados. Portanto, o medicamento atuou sôbre as manifestações depressivas em $80 \%$ dos pacientes tratados e, de modo bastante apreciável, em $60 \%$ dêles.

Esta pesquisa nos autoriza concluir que a $\alpha$-metilbenzilidrazina, agente psicanaléptico relativamente inócuo, empregado no tratamento de depressão em pacientes com neuroses e psicoses, mostrou-se útil, permitindo a remissão completa ou melhoras acentuadas em $60 \%$ dos casos. A maior eficácia da droga foi observada na depressão reativa.

\section{RESUMO}

É experimentado $\mathrm{nm}$ nôvo agente inibidor da monaminoxidase, a $\alpha$-metil-benzilidrazina. Foram estudados 20 pacientes com quadros depressivos 
(endógenos, involutivos, reativos, neuróticos e sintomáticos no curso de psicoses diversas). O medicamento foi utilizado em doses que variaram entre 10 e $20 \mathrm{mg} /$ dia, por via oral, em período que oscilou de 20 a 90 dias. Foi adotado o método de observação clínico-analítica na avaliação dos resultados. As melhores respostas terapêuticas foram observadas nos pacientes com depressão reativa e, a seguir, nos casos de depressão involutiva e neurótica. As depressōes surgidas no decurso de diferentes psicoses foram influenciadas de modo menos regular, sendo em geral pouco melhoradas ou não sofrendo qualquer influência.

\section{SUMMARY}

Clinical essay with $\alpha$-methyl-benzylhydrazine in in-patients.

The results with a new monoamine oxidase inhibitor ( $\alpha$-methyl-benzylhydrazine) on 20 depressed patients are reported. The doses used orally ranged from 10 to $20 \mathrm{mg} /$ day, during 20 to 90 days. The evalutation was made on the basis of clinical analytic observation. The results were as follow: very good improvement in 5 cases; 7 cases with good results; 4 cases with moderate improvement; 4 cases remained unchanged. The best results were observed in patients with reactive depression. Good results were observed in involutional and neurotic depressions. The symptomatic depressions arisig in the course of various psychoses were hardly, or not at all, influenced by the drug. Severe side effects were not present, except transitory jaundice observed in one case.

The authors concluded that $\alpha$-methyl-benzylhydrazine is a useful antidepressant drug in the treitment of depression, specially in reactive psychoses.

\section{REFERENCIAS}

1. AJURIAGUERRA, J. - Monoamines et structures anatomo-fonctionelles cérebrales. In Monoamines et Système Nerveux Central, Masson et Cie, editor, Genève, 1961, págs. 277-293.

2. PICHOT, P. - L'evaluation des modifications du comportement humain sous l'influence de drogues psychotropes. In Neuropsychopharmacology. E. Rothlin, editor, vol. 2, Elsevier Publishing Co., Amsterdam, 1961.

3. SIMōes, E. V.; Silva, B. B.; DOMINGUES, J. B.; SIlvA, P. \& CAPP, A. B. - Drogas psicotrópicas. Publicações Médicas 33:67-104, 1962.

Sanatório Anhembi - Rua Desembargador Vale 938 -- São Paulo, SP - Brasil. 